\title{
Democratic fallacy
}

\author{
Japan's effort to make budget allocations by public hearing could be good for \\ the country and for science, but not as currently planned.
}

T he Japanese government is attempting something that seems revolutionary, at least in Japan: to let people outside the bureaucracies observe its budgetary decision-making process and, even more radical, to involve the public in that process.

In hearings that started on 11 November and continue this week, working groups of non-government specialists and public representatives are grilling bureaucrats about 220 major government projects and weighing budget requests against their own estimates of their value. The groups have recommended cuts that are sometimes slight, sometimes deep and sometimes total. Just how much impact those recommendations will have on the finance ministry's 2010 budget decision, usually finalized by the end of December, is not yet clear.

The country's highest science policy-making body, the Council for Science and Technology Policy (CSTP), is responsible for the scientific re-evaluation of the projects - a counter or complement to the social evaluation' going on in the working groups. The presence of the finance minister on the Government Revitalization Unit, which oversees the working groups, has most observers convinced that the recommendations will carry hefty influence (see Nature 462, 258-259; 2009).

The process is being applied to dozens of science projects and to some of the most basic scientific-funding mechanisms. It is ruffling the feathers of a good proportion of the Japanese scientific community. Yet if implemented intelligently, it could be a positive development. Transparency and public involvement, both of which are weak in Japan, should certainly be encouraged. They help to ensure that decisions are made not through a deal between the head of an institute and bureaucrats, as sometimes happens in Japan, but rather on scientific need.

Before deciding how much weight to give these recommendations, however, the finance ministry should consider some major flaws in the process.

Can a bureaucrat, in one hour, explain a long-term project worth tens of millions of dollars - especially one that has existed for more than a decade, such as the SPring-8 synchrotron - to a group of
19 people, only a few of them scientists and none of them specialists in the fields in question, and hope that they will understand its importance? Can the judgement of that group, which in the case of the synchrotron was to cut the budget by a whopping $30-50 \%$, be considered conclusive? Can such a process adequately assess the repercussions of what these cuts would mean?

With regard to the country's supercomputer project, which would probably be terminated if the group's suggestions are followed, the group could be right to question the nationalistic phrase "fastest in the world" used to justify the programme. But there could be a case for the project to be rethought, reduced and renegotiated. On a smaller scale, it might still be able
"If the public is to evaluate scientists' way of doing things, then scientists should be given a chance to defend themselves." to benefit science enough to justify itself. Such negotiation, however, will require more scientific input than the new process allows, as even the CSTP is dominated by bureaucrats, generally without any scientific background, and representatives of industry.

Overall, the working groups have provided potentially useful feedback about the perceived social value of these projects. For large public investments such as those under scrutiny, that is an important perspective, and one that scientists often lose sight of. But dialogue needs to follow - if the public is to evaluate scientists' way of doing things, then scientists should be given a chance to defend themselves.

Perhaps, as one researcher described it, this is "a bad dream" and scientists will wake up in January to find that the government gave the recommendations due consideration before moving forwards. Perhaps, as the process settles into place in the years ahead, researchers will come to see it as an acceptable and surmountable challenge to justify their studies. But, as currently posed, the recommendations risk being the final word in a decision-making process that could have disastrous repercussions for decades to come.

\section{Conservative vacuum}

\section{Britain's main opposition party needs policies for research and for universities.}

ast year, Britain's higher-education sector generated around $£ 33$ billion (US $\$ 55$ billion) of the UK gross domestic product, _ putting it ahead of the aircraft, advertising and pharmaceutical industries, according to figures published earlier this month by economists at the University of Strathclyde, UK. It is astonishing, then, that with all the Conservative Party's rhetoric on how it intends to drag Britain out of recession, it hasn't formulated policy on universities and research. And yet there is a strong possibility that the Conservatives will be leading the country by June next year.

The next government needs to have a long-term vision for the role of science. The Labour government took a bold and welcome move with the 2004 publication of its 10 -year science and innovation framework. Any new government must either carry this torch forwards or light a new one. Through the framework, priorities for science and the direction the government wanted to focus on were set in the appropriate long-term context.

At the same time, government spending on research and development (R\&D) was ring-fenced and surged to more than $£ 3$ billion 